\title{
DINAMIKA KELOMPOK TANI SARONGSONG YOUTH DI KELURAHAN TUMATANGTANG SATU, KECAMATAN TOMOHON SELATAN, KOTA TOMOHON
}

\author{
Charly Kojansow \\ Jenny Baroleh \\ Martha M. Sendow
}

\begin{abstract}
This research aims to know the dynamics of farmer groups Sarongsong Youth in Tumatangtang One Vilage Sub-District South Tomohon. This research method was using study case. Data is taken from primary data and secondary data from February 2016 until April 2016, primary data was conducted with interview techniques using a list of questions while the secondary data were taken from the Office of Neighborhood, Office districts and local Office of Agricultural Extension, Fisheries and Forestry (BP3K). All members of the Group of farmers Sarongsong Youth Tumatangtang Villages One Sub-district South Tomohon became the source of the respondents in this study. Variable research includes the 8 (eight) factor is the dynamics of farmer groups, namely: the purpose of the group, group structure, group functions, the function of the coaching group, group cohesiveness, the atmosphere, the pressure group on a group of farmers, farmer groups and effectiveness. The data obtained in the analyses are descriptive, and the results obtained are presented in the form of a percentage of the Table. The research results showed that farmers group dynamics Sarongsong Youth in Tumatangtang Neighborhoods One Sub-district South Tomohon is a good category. This is especially shown by factors the dynamics of farmer groups in addition to the pressure on the group, which is due more to sub factor is still less. Farmers group dynamics Sarongsong Youth needs to be improved again, especially the factor of pressure on the group. Should be given its own awards to members of the other groups in order to provide more motivation for them is appropriate, especially when there are more who contribute to a group.
\end{abstract}

Keyword: the dynamics of farmer groups, Sarongsong Youth, Urban village of Tumatangtang Satu, Tomohon City

\section{ABSTRAK}

Penelitian ini bertujuan untuk mengetahui dinamika kelompok tani Sarongsong Youth di Kelurahan Tumatangtang Satu Kecamatan Tomohon Selatan. Penelitian ini menggunakan metode studi kasus. Data yang diambil berupa data primer dan data sekunder yang diambil dari bulan Februari 2016 sampai dengan bulan April 2016, data primer dikumpulkan dengan teknik wawancara menggunakan daftar pertanyaan sedangkan data sekunder diperoleh dari Kantor Kelurahan Tumatngtang Satu, Kantor Kecamatan Tomohon Selatan dan Kantor Balai Penyuluhan Pertanian, Perikanan dan Kehutanan (BP3K) setempat. Seluruh anggota kelompok Tani Sarongsong Youth Kelurahan Tumatangtang Satu Kecamatan Tomohon Selatan menjadi sumber Responden dalam penelitian ini. Variable penelitian mencakup 8 (delapan) unsur dinamika kelompok tani, yaitu: tujuan kelompok, struktur kelompok, fungsi tugas kelompok, fungsi pembinaan kelompok, kekompakan kelompok, suasana kelompok, tekanan pada kelompok tani, dan efektivitas kelompok tani. Data yang diperoleh di analisis secara deskriptif, dan hasil yang diperoleh disajikan dalam bentuk Tabel Presentase. Hasil penelitian menunjukan bahwa dinamika kelompok tani Sarongsong Youth di Kelurahan Tumatangtang Satu berada pada kategori yang baik. Hal ini terutama ditunjukan oleh faktor-faktor dinamika kelompok tani selain tekanan pada kelompok, yangt disebabkan lebih kepada sub-faktor penghargaan yang masih kurang baik. Dinamika kelompok tani Sarongsong Youth perlu ditingkatkan lagi,apalagi dalam faktor tekanan pada kelompok. Sebaiknya diberikan penghargaan terdiri bagi anggota kelompok yang lainnya agar dapat memberikan motivasi yang lebih lagi bagi mereka yang pantas, terutama ketika ada yang memberikan kontribusi lebih pada kelompok

Kata kunci: Dinamika Kelompok Tani, Sorongsong Youth, Kelurahan Tumatanggang Satu, Kota Tomohon 


\section{PENDAHULUAN}

\section{Latar Belakang}

Dalam meningkatkan dan melestarikan suasembada pangan di Indonesia, maka pembinaan terhadap petani tetap menjadi pusat perhatian (central issue). Selain itu dalam rangka pembangunan nasional secara menyeluruh, para petani juga menjadi pusat perhatian karena mereka menempati proporsi terbesar dalam strukrur penduduk Indonesia. Petani menduduki posisi penting dalam produksi pertanian, dimana petani selain sebagai jurutani, ia juga sebagai manajer dalam usaha taninya. Segala sesuatu menyangkut produksi usaha taninya diputuskan oleh petani itu sendiri bersama-sama dengan keluarganya.Oleh karena itu untuk menetapkan posisi dan peranannya maka dirasa perlu untuk meningkatkan upaya pembinaan terhadap petani dan keluarganya melalui kegiatan penyuluhan pertanian.

Pemerintah dalam hal ini Departemen Pertanian menggiatkan program penyuluhan dengan berbagai metode.Salah satu metode yang digunakan adalah metode penyuluhan kelompok. Karena metode ini lebih efektif dan efisien dengan metode lain, seperti metode perorangan dan masal. Mengingat jumlah petani di Indonesia yang cukup banyak, sementara petugas penyuluh pertanian tersedia dalam jumlah yang relative terbatas, maka penyuluhan di Indonesia adalah melalui pendekatan kelompok, dengan tidak mengesampingkan pendekatan perorangan dan masal. Hal ini juga di Kecamatan Tomohon Selatan dengan jumlah penduduk yang bekerja sebagai petani sekitar 2.447 orang sampai tahun 2015 memiliki 95 kelompok tani yang terbagi atas kelompok tani pemula, lanjut dan utama yang dilayani oleh 12 penyuluh yang terbagi pada 12 Kelurahan.

Kelurahan Tumatangtang Satu adalah salah satu Kelurahan di Kecamatan Tomohon Selatan yang memiliki 10 kelompok tani yang terdiri atas 4 kelompok tani lanjut, dan 6 kelompok tani pemula serta dilayani oleh seorang penyuluh lapangan. Konsep yang menunjukan keefektifan kelompok dalam mencapai tujuan-tujuannya adalah konsep dinamika kelompok. Suatu kelompok ataupun organisasi dapat dikatakan dinamis apabila kelompok atau organisasi itu efektif dalam mencapai tujuannya. Aspek dinamika kelompok ini memberikan peluang atau kesempatan sebesar-besarnya kepada anggota untuk bekerjasama dan berpartisipasi dalam kegiatankegiatan kelompok.

Kelompok tani Sarongsong youth sendiri merupakan salah satu kelompok tani yang tergolong unik, dimana kelompok ini merupakan sekelompok pemuda gereja yang membentuk kelompok tani. Sebagian besar anggota kelompok ini merupakan petani yang tergolong baru dan tidak dilatar belakangi sebagai petani sebelumnya, status kebanyakan anggotanya pun adalah mahasiswa. Seperti yang di jelaskan oleh ketua kelompok tani Sarongsong youth, sejak berdiri pada 13 maret 2014 awalnya kelompok ini hanya beranggotakan 15 orang. Akan tetapi dengan adanya bantuan dari pemerintah yang dirasa sangat membantu dalam mengembangkan usaha tani.Kelompok tani Sarongsong youth menambah anggotanya menjadi 32 orang, dan membentuk koprasi.

Kelompok tani Sarongsong youth mampu memberdayakan pemuda-pemuda gereja dalam kegiatan yang positif dan kelompok tani Sarongsong youth benar-benar memanfaatkan peluang yang ada serta tetap berusaha mempertahankan eksistensi mereka, terbukti dengan dibentuknya koperasi sebagai sumber pendapatan lain dengan membuka usaha pangkalan gas dan ternak ayam sebagai solusi pada musim kemarau panjang yang terjadi pada tahun 2015 yang menyebabkan mereka tidak bisa bertani. Jika melihat bagaimana kelompok tani ini terus bertahan dan mengembangkan usaha tani mereka, kelompok tani Sarongsong youth dapat dijadikan contoh kelompok tani yang mandiri meskipun kelompok ini anggotanya tidak memiliki latar belakang sebagai seorang petani.

\section{Perumusan Masalah}

Bagaimanakah dinamika kelompok tani Sarongsong youth di Kelurahan Tumatangtang Satu Kecamatan Tomohon Selatan. 


\section{Tujuan Penelitian \\ Penelitian ini bertujuan untuk
mengetahui dinamika kelompok tani Sarongsong youth.}

\section{Manfaat Penelitian}

Adapun hasil penelitian ini diharapkan dapat bermanfaat bagi kelompok tani Sarongsong youth dalam meningkatkan dan mengembangkan usaha taninya, berguna untuk bahan penelitian selanjutnya serta dapat berguna bagi pemerintah atau pengambil kebijakan di daerah terlebih khususnya di bidang pertanian.

\section{METODOLOGI PENELITIAN}

\section{Metode Pengumpulan Data}

Penelitian ini menggunakan metode studi kasus.Data yang diambil adalah data primer dan data sekunder.Data primer dilakukan dengan teknik wawancara yang menggunakan daftar pertanyaan, sedangkan data sekunder diambil dari instansi terkait.

\section{Metode Pengambilan Contoh}

Seluruh anggota kelompok tani Sarongsong youth Kelurahan Tumatangtang 1 kecamatan Tomohon selatan menjadi responden dalam penelitian ini.

\section{Konsep Pengukuran Variabel}

Variable penelitian mencakup 8 (delapan) faktor dinamika kelompok tani, yaitu:

a. Tujuan Kelompok, tujuan kelompok ini untuk melihat apakah tujuan kelompok sesuai dengan tujuan individu atau tidak sesuai dengan tujuan dari individu.

b. Struktur Kelompok, struktur kelompok adalah bentuk hubungan antara inidividuindividu anggota kelompok yang dapat menciptakan interaksi dalam kelompok :

1. Pengambilan keputusan. Apakah anggota mendapat kesempatan dalam mengambil keputusan atau tidak.

2. Pembagian tugas. Apakah anggota kelompok merasa mendapat pembagian tugas atau tidak merasa mendapat bagian tugas.

3. Komunikasi. Hal ini dimaksudkan dalam struktur kelompok adalah alur komunikasi dalam bentuk informasi yang dapat berguna bagi kelompok apakah anggota ikut mencari informasi atau tidak mencari informasi.

c. Fungsi Tugas Kelompok, fungsi tugas kelompok adalah semua kegiatan yang dilakukan kelompok sehingga tujuan individu dan kelompok dapat tercapai, hal ini masi berkaitan erat dengan alur komunikasi dalam kelompok.

1. Fungsi informasi. Hal ini untuk memastikan apakah setiap anggota kelompok menerima informasi yang berasal dari kelompok atau tidak mendapat informasi.

2. Fungsi menjelaskan. bertujuan untuk mengetahui apakah informasi yang disampaikan ikut dijelaskan kepada anggota yang lainnya atau tidak.

3. Fungsi memuaskan anggota. Fungsi ini untuk melihat apakah anggota kelompok merasa puas dengan informasi dan fasilitas yang ada dalam kelompok atau tidak merasa puas.

a. Fungsi Pembinaan Kelompok, pembinaan kelompok adalah usaha-usaha yang berorientasi memelihara dan mengembangkan kehidupan kelompok dengan mengadakan kegiatan-kegiatan rutin.

1. Keaktifan anggota dalam pertemuan kelompok. Fungsi ini untuk melihat apakah anggota aktif atau tidak aktif dalam pertemuan kelompok.

2. Keaktifan anggota dalam kegiatan kelompok. Fungsi ini untuk melihat apakah anggota aktif atau tidak aktif dalam kegiatan kelompok.

3. Keaktifan pengawasan kegiatan dalam kelompok. Fungsi ini untuk melihat apakah setiap anggota diawasi dalam kegiatan kelompok atau tidak..

a. Kekompakan Kelompok, yang dimaksud adanya rasa keterikatan yang kuat antara anggota dan kelompoknya.

1. Tingkat kepercayaan terhadap pimpinan kelompok pada anggotanya dan anggota 
terhadap pimpinan. Hal ini dapat dilihat dengan pandangan anggota terhadap pimpinan kelompok apakah sudah bisa dijadikan panutan atau tidak.

2. Anggota mendapat bagian dalam menyusun rencana dan program kelompok.

3. Mendapat bagian atau tidak mendapat bagian.

b. Suasana Kelompok

1. Hubungan baik antara anggota kelompok adalah untuk melihat hubungan dalam kelompok apakah baik atau tidak baik.

2. Keadaan lingkungan fisik dalam satu Kelurahan adalah untuk melihat apakah anggota kelompok kerada dalam satu linkungan fisik tau tidak.

c. Tekanan Pada Kelompok Tani, tekanan pada petani meliputi pemberian penghargaan bagi para anggota yang berprestasi atau memiliki kontribusi lebih dalam kelompok dan hukuman atau sanksi bagi anggota yang melanggar norma atau aturan yang disepakati.

1. Penghargaan bagi anggota yang rajin dalam kegiatan dan memenuhi semua kewajiban, mendapat penghargaan atau tidak mendapat penghargaan

2. Sanksi bagi anggota yang tidak rajin dalam kegiatan dan tidak memenuhi kewajiban, apakah mendapatkan sanksi atau tidak.

d. Efektifitas Kelompok Tani, efektifitas kelompok tani dapat di bagi ke dalam dua aspek sebagai indikatornya, yaitu :

1. Produktifitas yang diukur berdasarkan keberhasilan kelompok tani dalam mencapai tujuan kelompok. Fungsi ini untuk melihat apakah tujuan kelompok dapat tercapai atau tujuan kelompok tidak tercapai.

2. Moral kelompok. Fungsi ini untuk melihat perasaan bangga anggota terhadap pencapain tujuan kelompok, apakah anggota merasa bangga atau tidak merasa bangga dengan kelompoknya.

\section{Analisis Data}

Data yang diperoleh dianalisis secara deskripsi, dimana hasil yang diperoleh disajikan dalam bentuk Tabel Presentase berdasarkan hasil kualifikasi sub faktor dan faktor-faktor dinamika.

\begin{tabular}{l|ll}
$\begin{array}{l}\text { Kualifikasi faktor- } \\
\text { faktor dinamika } \\
\text { kelompok: }\end{array}$ & $\begin{array}{l}\text { Kualifikasi sub } \\
\text { faktor dinamika } \\
\text { kelompok: }\end{array}$ \\
$0 \quad-25 \% \quad$ tidak & $\begin{array}{llll}0-25 \% & \text { tidak } \\
\text { baik } & \text { baik } & \\
26-60 \% & \text { kurang } & -60 \% & \text { kurang } \\
51-75 \% & \text { sedang } & 51-75 \% & \text { sedang } \\
76-100 \% & \text { baik } & 76-100 \% & \text { baik }\end{array}$
\end{tabular}

\section{Waktu Dan Tempat Penelitian}

Penelitian ini dilaksanakan di Kelurahan Tumatangtang 1 Kecamatan Tomohon Selatan dari bulan Febuari 2016 sampai bulan April 2016, mulai dari persiapan penelitian, pengambilan data dan penulisan laporan penelitian.

\section{HASIL DAN PEMBAHASAN}

\section{Deskripsi Wilayah Penelitian}

\section{Keadaan Geografis Kecamatan Tomohon Selatan}

Kecamatan Tomohon Selatan memiliki pemerintahan sebanyak 12 Kelurahan. Kecamatan Tomohon Selatan berada di wilayah pemerintahan Kota Tomohon Provinsi Sulawesi utara. Jarak pemerintahan wilayah Kecamatan Tomohon Selatan dengan Pusat pemerintahan Kota Tomohon yaitu $\pm 1,5 \mathrm{Km}$ dan Jarak ke Ibu Kota Provinsi yaitu $\pm 23,5 \mathrm{Km}$.

Wilayah Kecamatan Tomohon Selatan mempunyai batas-batas wilayah sebagai berikut:

Sebelah Utara : Berbatasan dengan

Kecamatan Tomohon Tengah.

Sebelah Timur : Berbatasan dengan

Kecamatan Tomohon Tengah.

Sebelah Selatan : Berbatasan dengan

Kabupaten Minahasa.

Sebelah Barat : Berbatasan dengan Tomohon Barat.

Kecamatan Tomohon Selatan Termasuk daerah yang beriklim tropis, dengan musim 
penghujan terjadi pada bulan Oktober sampai dengan bulan Maret, dan musim kemarau terjadi pada bulan April sampai dengan bulan September.

Kecamatan Tomohon Selatan berada pada $1^{\circ} 15^{\prime}$ Lintang Utara dan $124^{\circ} 50^{\prime}$ Bujur Timur, letak Kecamatan Tomohon Selatan berada pada ketinggian $\pm 700-800$ meter dari permukaan laut. Suhu di Kota Tomon bias mencapai $30^{\circ}$ Celsius pada siang hari dan $23^{\circ}$ $24^{\circ}$ Celsius pada malam hari.

\section{Deskripsi Umum Kelurahan Tumatangtang Satu}

a. Keadaan Geografis. Kelurahan Tumatangtang Satumerupakan salah satu Kelurahan yang berada di Kecmatan Tomohon Selatan yang memiliki batas-batas wilayah sebagai berikut:

Sebelah Utara : Berbatasan dengan Kelurahan Tumatangtang.

Sebelah Timur : Berbatasan dengan Kelurahan Tumatangtang.

Sebelah Selatan : Berbatasan dengan Kelurahan Lahendong dan Kelurahan Kampung jawa.

$\begin{aligned} & \text { Sebelah Barat } \quad \text { Berbatasan dengan } \\ & \text { Kelurahan Kampung Jawa } \\ & \text { dan Kelurahan Pinaras. }\end{aligned}$

Luas wilayah Kelurahan Tumatangtang Satu adalah 180 hektardengan rincian pemukiman 28 hektar, persawahan 16 hektar, perkebunan 134 hektar, perkantoran 0,5 hektar, kuburan 1,5 hektar dan pekarangan seluas 2 hektar. Jumlah penduduk sampai tahun 2015 bejumlah 1625 jiwa yang terdiri dari 854 lakilaki dan 791 perempuan dengan jumlah kepala keluarga $446 \mathrm{KK}$.

b. Perekonomian. Mata pencaharian penduduk Kelurahan Tumatangtang Satu sebagian besar bersumber dari pertanian, baik bertani maupun menjadi buruh tani. Gambaran mengenai distribusi pendapatan penduduk Kelurahan Tumatangtang Satu, dapat dilihat pada Tabel 1.
Tabel 1. Mata pencaharian penduduk Kelurahan Tumatangtang Satu, Tahun 2015

\begin{tabular}{|c|c|c|c|}
\hline No & $\begin{array}{c}\text { Mata } \\
\text { Pencaharian }\end{array}$ & $\begin{array}{l}\text { Jumlah } \\
\text { (Orang) }\end{array}$ & $\begin{array}{c}\text { Persentase } \\
(\%)\end{array}$ \\
\hline 1. & Tani & 184 & 39 \\
\hline 2. & Buruh Tani & 77 & 16,31 \\
\hline 3. & PNS & 59 & 12,5 \\
\hline 4. & $\begin{array}{l}\text { Pengrajin } \\
\text { Industri } \\
\text { Rumah } \\
\text { Tangga }\end{array}$ & 2 & 0,42 \\
\hline 5. & Peternak & 3 & 0,64 \\
\hline 6. & POLRI & 6 & 1,27 \\
\hline 7. & Perawat & 8 & 0,69 \\
\hline 8. & Dosen & 3 & 0,64 \\
\hline 9. & Pengusaha & 4 & 0,85 \\
\hline 10. & Montir & 3 & 0,64 \\
\hline 11. & $\begin{array}{l}\text { Pensiunan } \\
\text { PNS/TNI/PO } \\
\text { LRI }\end{array}$ & 14 & 2,97 \\
\hline 12. & $\begin{array}{l}\text { Karyawan } \\
\text { Swasta }\end{array}$ & 103 & 21,82 \\
\hline 13. & $\begin{array}{l}\text { Karyawan } \\
\text { Perusahaan } \\
\text { Pemerintah } \\
\end{array}$ & 6 & 1,27 \\
\hline & Total & 472 & 100 \\
\hline
\end{tabular}

Berdasarkan Tabel 1 dapat dilihat bahwa sebagian besar atau sebesar 39\% penduduk Kelurahan Tumatangtang Satu memiliki mata pencaharian sebagai petani dan sebesar $16,31 \%$ sebagai buruh tani, hal ini menunjukan bahwa sector pertanian memegang peran penting sebagai sumber mata pencaharian utama penduduk Kelurahan Tumatangtang Satu.

c. Agama . Dari Tabel 2 di bawah ini, dapat dilihat bahwa agama dari penduduk Kelurahan Tumatangtang Satu sebagian besar memeluk Kristen Protestan dengan persentase sebesar 63,75 \%. Meskipun terdapat tiga golongan agama dan di dominasi oleh golongan agama Kristen protestan akan tetapi kerukunan di Kelurahan Tumatangtang Satu tetap terjaga. 
Tabel 2. Golongan Agama di Kelurahan Tumatangtang Satu, Tahun 2015

\begin{tabular}{llcc}
\hline $\mathrm{N}$ & $\begin{array}{l}\text { Golonga } \\
\mathrm{n} \text { Agama }\end{array}$ & $\begin{array}{c}\text { Jumlah } \\
\text { Pemeluk } \\
\text { (Orang) }\end{array}$ & $\begin{array}{c}\text { Persentase } \\
(\%)\end{array}$ \\
\hline 1. & $\begin{array}{l}\text { Islam } \\
\text { Kristen }\end{array}$ & 56 & 3,45 \\
2. & $\begin{array}{l}\text { Protesta } \\
\mathrm{n}\end{array}$ & 1036 & 63,75 \\
3. & Katholik & 533 & 32,8 \\
\hline & Total & 1625 & 100 \\
\hline
\end{tabular}

Sumber: Kantor Kelurahan Tumatangtang Satu, Tahun 2015

Deskripsi Kelompok Tani Sarongsong youth.

\section{Waktu Pendirian}

Kelompok Tani Sarongsong Youth didirikan pada tanggal 13 April 2014

\section{Keangotaan}

Anggota kelompok tani Sarongsong youth merupakan sebagian anggota pemuda Gereja GMIM Sarongsong Tumatangtang yang membentuk kelompok tani.

\section{Kepengurusan}

Pengurus kelompok tani Sarongsong Youth terdiri dari Ketua, Sekretaris dan Bendahara yang dipilih oleh semua anggota kelompok.

\section{Tujuan Kelompok Tani Sarongsong youth}

Tujuan kelompok tani Sasrongsong Youth adalah memberdayakan pemuda-pemuda GMIM Sarongsong Tumatangtang ke dalam kegiatan yang positif, dan mengangkat keberadaan anggotanya baik dari segi ekonomi maupun sosial.

\section{Kegiatan Kelompok Tani}

Kelompok tani Sarongsong Youth telah melakukan beberapa kegiatan dalam usaha mencapai tujuan kelompok. Kegiatan yang pernah dilakukan yaitu usahatani menanam cabai, beternak ayam, membuka pangkalan gas, usaha memasarkan hasil dari pertanian dan peternakan ayam yang dihasilkan oleh kelompok ini.

\section{Struktur Organisasi}

KETUA

\section{SEKRETARIS}

\section{BENDAHAR}

\section{ANGGOTA}

\section{Karakteristik Anggota Kelompok Tani Sarongsong youth}

\section{Pendidikan}

Efferson

(Hutauruk, 2009), mengatakan bahwa tingkat pendidikan baik formal maupun non formal besar sekali pengaruhnya terhadap penyerapan ide-ide baru, sebab pengaruh pendidikan terhadap seseorang akan memberikan suatu wawasan yang luas, sehingga petani tidak mempunyai sifat yang tidak terlalu tradisional.

Dengan demikian tingkat pendidikan masyarakat merupakan salah satu aspek yang mempengaharui pola piker seseorang dalam menentukan keputusan menerima inovasi baru, karena semakin tinggi tingkat pendidikan seseorang diharapkan dapat berpikir lebih baik dan lebih mudah menyerap inovasi pertanian yang berkaitan dengan usahataninya. Mereka yang berpendidikan tinggi biasanya lebih cepat dalam melakukan adopsi inovasi. Begitupun sebaliknya mereka yang berpendidikan rendah, agak sulit dan memakan waktu relative lebih lama dalam melakukan perubahan.

$$
\text { Petani yang memiliki tingkat }
$$
pendidikan formal yang tinggi memiliki kemampuan yang lebih baik dalam mengelola usahataninya, selain itu petani dapat mengambil keputusan-keputusan dan mengatasi masalah-masalah yang terjadi. 


\section{Tabel 3. Presentase Responden Menurut Tingkat Pendidikan}

\begin{tabular}{ccc}
\hline $\begin{array}{c}\text { Tingkat } \\
\text { Pendidikan } \\
\text { Terakhir }\end{array}$ & $\begin{array}{c}\text { Responden } \\
\text { (Orang) }\end{array}$ & $\begin{array}{c}\text { Presentase } \\
(\%)\end{array}$ \\
\hline SMP & 2 & 5,72 \\
SMA & 30 & 85,71 \\
$\begin{array}{c}\text { Perguruan } \\
\text { Tinggi }\end{array}$ & 3 & 8,57 \\
\hline Total & 35 & 100 \\
\hline
\end{tabular}

Sumber: Data Primer, Tahun 2016

Berdasarkan Tabel 3 dapat dilihat bahwa semua anggota kelompok tani Sarongsong Youth pernah mengikuti pendidikan formal. Tingkat pendidikan dari anggota kelompok tani Sarongsong youth..

Dari Tabel 3 dapat dilihat bahwa semua anggota kelompok tani Sarongsong Youth pernah mengikuti pendidikan formal. Tingkat pendidikan dari anggota kelompok tani ini adalah Sekolah Menengah Pertama yang terendah dan Perguruan Tinggi tingkat pendidikan anggotanya, akan tetapi sebesar 85\% anggota kelompok tani ini berpendidikan akhir Sekolah Menengah Atas. Meskipun demikian kebanyakan yang berpendidikan akhir Sekolah Menengah Atas sedang melanjutkan studi di Perguruan Tinggi.

\section{Umur}

Umur petani akan mempengaruhi kemampuan fisik bekerja dan berpikir. Pada umumnya petani yang berusia lebih muda akan memiliki fisik yang lebih kuat dari petani yang berumur tua.

Tabel 4. Prentase Responden Menurut Umur

\begin{tabular}{ccc}
\hline Umur & $\begin{array}{c}\text { Responden } \\
(\text { Orang) }\end{array}$ & $\begin{array}{c}\text { Presentase } \\
(\%)\end{array}$ \\
\hline $19-24$ & 29 & 82,86 \\
$25-30$ & 4 & 11,42 \\
$31-36$ & 2 & 5,72 \\
\hline Total & 35 & 100 \\
\hline
\end{tabular}

Sumber: Data Primer, Tahun 2016
Dari Tabel 4 dapat dilihat bahwa umur anggota kelompok tani Sarongsong Youth berada pada tingkat umur yang masih muda dan produktif. Hal ini dapat berdampak positif bagi kelompok tani ini dalam menjalankan usaha tani mereka.

\section{Mata Pencarian}

Perbedaan mata pencaharian atau pekerjaan utama anggota kelompok tani akan berpengaruh terhadap pendapatan antara petani itu sendiri, hal ini juga bias mempengaharui kontribusi anggotanya terhadap kelompok tani.

\section{Tabel 5. Presentase Responden Berdasarkan Pekerjaan/Mata Pencaharian}

\begin{tabular}{ccc}
\hline Pekerjaan & $\begin{array}{c}\text { Responden } \\
\text { (Orang) }\end{array}$ & $\begin{array}{c}\text { Presentase } \\
(\%)\end{array}$ \\
\hline Swasta & 2 & 5,72 \\
$\begin{array}{c}\text { Mahasiswa/Pe } \\
\text { lajar }\end{array}$ & 28 & 80 \\
Pengangguran & 5 & 14,28 \\
\hline Total & 35 & 100 \\
\hline
\end{tabular}

Sumber: Data Primer, Tahun 2016

Dari Tabel 5 dapat dilihat bahwa anggota kelompok tani Sarongsong youth didominasi mahasiswa dan pelajar yang belum bekerja yaitu sebesar $80 \%$, hal itu disebabkan status mereka yang masih mengemban ilmu di Perguruan Tinggi, hanya 5,72\% saja yang telah bekerja dan 14,28\% merupakan pengangguruan dikarenakan anggota tersebut baru menyelesaikan studi di Sekolah Menengah Atas dan tidak melanjutkan studi ke jenjang yang lebih tinggi. Tenaga kerja mencakup penduduk yang sudah atau sedang bekerja, yang sedang bekerja mencari pekerjaan, dan yang melakukan kegiatan lain seperti bersekolah dan mengurus rumah tangga menurut Payaman (Kusumastuti, 2012). 


\section{Faktor-Faktor Dinamika Kelompok Tani Sarongsong youth}

a. Tujuan Kelompok. Tujuan Kelompok merupakan salah satu unsur dinamika kelompok yang menggambarkan tentang suatu hasil yang ingin dicapai oleh kelompok. Tujuan kelompok harus sesuai dengan tujuan anggota kelompok agar supaya tujuan kelompok cepat tercapai.

\begin{tabular}{lcc}
\multicolumn{3}{c}{$\begin{array}{c}\text { Tabel 6. Prensentase Kesesuaian Tujuan } \\
\text { Anggota Kelompok Dengan Tujuan } \\
\text { Kelompok }\end{array}$} \\
\hline Kesesuaian & $\begin{array}{c}\text { Responden } \\
\text { (Anggota) }\end{array}$ & $\begin{array}{c}\text { Presentase } \\
(\%)\end{array}$ \\
\hline $\begin{array}{l}\text { Sesuai } \\
\text { Tidak } \\
\text { Sesuai }\end{array}$ & 35 & 100 \\
\hline \multicolumn{1}{c}{ Total } & 0 & 0 \\
\hline
\end{tabular}

Sumber: Data Primer, Tahun 2016

Berdasarkan Tabel 6, dapat dilihat tujuan kelompok tani Sarongsong youth telah sesuai dengan tujuan semua anggotanya. Kelompok tani ini pertama kali melakukan usahatani dengan modal bibit cabai dari bantuan pemerintah dan memanfaatkan lahan tidur, atau lahan yang tidak dipakai oleh petani yang masih merupakan anggota jemaat Gereja Sarongsong Tumatangtang.

b. Struktur Kelompok. Struktur kelompok dapat dilihat dari tiga sub faktor, yaitu struktur pengambilan keputusan, struktur tugas atau pembagian pekerjaan dan struktur komunikasi.

Sub faktor yang pertama adalah struktur pengambilan keputusan, dapat diketahui dari siapa saja yang ikut serta dalam mengambil keputusan dalam kelompok, keputusan disini adalah hal-hal yang berkaitan dengan pemecahan masalah kelompok.

Pengambilan keputusan dalam kelompok tani Sarongsong youth dilakukan melalui kegiatan pertemuan yang dilakukan satu minggu satu kali.
Tabel 7. Presentase Responden Dalam Pengambilan Keputusan

\begin{tabular}{lcc}
\hline \multicolumn{1}{c}{$\begin{array}{c}\text { Pengambilan } \\
\text { Keputusan }\end{array}$} & $\begin{array}{c}\text { Responden } \\
\text { (Anggota) }\end{array}$ & $\begin{array}{c}\text { Presentase } \\
(\%)\end{array}$ \\
\hline $\begin{array}{l}\text { Mengambil } \\
\text { Keputusan }\end{array}$ & 32 & 91,43 \\
$\begin{array}{l}\text { Tidak } \\
\text { Mengambil } \\
\text { Keputusan }\end{array}$ & 3 & 8,57 \\
\hline \multicolumn{1}{c}{ Total } & 35 & 100 \\
\hline
\end{tabular}

Sumber: Data Primer, Tahun 2016

Dari Tabel 7 dapat dilihat bahwa 91,43\% responden ikut terlibat dalam pengambilan keputusan di dalam kelompok.

Sub faktor yang kedua adalah sturuktur tugas atau pembagian pekerjaan dalam kelompok, tugas yang dimaksud adalah dengan menjadi pengurus, kordinator kegiatan dan mendapat tugas dalam kegiatan lainya yang berguna bagi kelompok seperti mendapat tugas mengikuti penyuluhan dan lainya.

Presentase struktur tugas dalam kelompok tani Sarongsong youth dapat dilihat pada Tabel 8.

Tabel 8. Presentase Responden yang Mendapat Tugas

\begin{tabular}{lcc}
\hline \multicolumn{1}{c}{ Tugas } & $\begin{array}{c}\text { Responden } \\
\text { (Anggota) }\end{array}$ & $\begin{array}{c}\text { Presentase } \\
(\%)\end{array}$ \\
\hline $\begin{array}{l}\text { Mendapat } \\
\text { Tugas }\end{array}$ & 17 & 48,57 \\
$\begin{array}{l}\text { Tidak } \\
\text { Mendapat } \\
\text { Tugas }\end{array}$ & 18 & 51,43 \\
\hline \multicolumn{1}{c}{ Total } & 35 & 100 \\
\hline
\end{tabular}

Sumber: Data Primer, Tahun 2016 
Tabel 8 Menunjukan bahwa dari pertama kali diibentuk kelompok tani Sarongsong youth hanya sebesar $42,86 \%$ yang mendapat tugas atau hanya 17 orang saja yang mendapat tugas yaitu 3 orang yang menjadi pengurus (Ketua, Sekretaris, Bendahara), 3 orang menjadi kordinator dalam proses bertani capai, 1 orang sebagai kordinator dalam usaha peternakan ayam, 1 orang kordinator dalam usaha pangkalan gas dan 6 orang yang ditugaskan mengikuti pelatihan yang dilaksanakan oleh Dinas Pertanian dan 3 orang lainnya pernah mendapat tugas dalam usaha memasarkan cabai hasil pertanian kelompok. Anggota kelompok lainnya yang belum mendapat tugas karena belum adanya pemilihan ketua kelompok tani yang baru dan belum adanya pergantian kordinator serta pengurus.

Sub faktor ketiga adalah struktur komunikasi yang dapat diketahui dari arus komunikasi yang terjadi dalam kelompok. Komunikasi yang baik dalam kelompok apabila banyak responden yang mencari informasi baik melalui antar pribadi maupun media masa dan elektronik yang diserap oleh dirinya sendiri dan dibagikan kepada anggota kelompok yang lain. Jadi faktor dalam struktur komunikasi yakni bagaimana setiap anggota ikut mencari dan membagikan informasi yang bertujuan dapat berguna bagi kelompok.

\section{Tabel 9. Presentase Responden Dalam Mencari Informasi}

\begin{tabular}{lcc}
\hline \multicolumn{1}{c}{$\begin{array}{c}\text { Arus } \\
\text { Informasi }\end{array}$} & $\begin{array}{c}\text { Responden } \\
\text { (Anggota) }\end{array}$ & $\begin{array}{c}\text { Presentase } \\
(\%)\end{array}$ \\
\hline $\begin{array}{l}\text { Mencari } \\
\text { Informasi }\end{array}$ & 32 & 91,43 \\
$\begin{array}{l}\text { Tidak Mencari } \\
\text { Informasi }\end{array}$ & 3 & 8,57 \\
\hline \multicolumn{1}{c}{ Total } & 35 & 100 \\
\hline
\end{tabular}

Sumber: Data Primer, Tahun 2016
Dari Tabel 9, dapat dilihat bahwa tidak semua anggota kelompok tani ikut mencari informasi dikarenakan ada tiga orang anggota yang masih merasa malu-malu, dikarenakan usia mereka paling muda dari anggota lainnya. Anggota lainnya yang mencari informasi menyampaikannya dalam pertemuan kelompok. Informasi yang diperoleh oleh anggota kelompok berasal dari media social, bertanya kepada orang tua dan membaca koran.

c. Fungsi Tugas Kelompok. Fungsi tugas kelompok dapat dilihat dari tiga sub faktor yang terdiri dari fungsi tugas kelompok dalam memberikan informasi, fungsi menjelaskan dan fungsi memuaskan anggotanya. Fungsi tugas kelompok ini merupakan semua kegiatan yang harus dilakukan agar tujuan dari kelompok dapat tercapai.

Fungsi tugas kelompok dalam member informasi ini berasal dari anggota-anggota kelompok yang dibahas bersama ataupun informasi yang berasal dari luar anggota kelompok tani, informasi yang berasal dari anggota kelompok seperti yang dijelaskan pada struktur komunikasi. Sedangkan informasi yang didapat dari luar biasanya dari informasi yang diberikan oleh penyuluh pendamping. Hal ini dapat berjalan dengan baik apabila informasi itu dapat diterima dengan baik oleh setiap anggota kelompok.

\section{Tabel 10. Persentase Responden Yang Menerima Informasi Dari Kelompok}

\begin{tabular}{lcc}
\hline \multicolumn{1}{c}{ Tugas } & $\begin{array}{c}\text { Responden } \\
\text { (Anggota) }\end{array}$ & $\begin{array}{c}\text { Presentase } \\
(\%)\end{array}$ \\
\hline $\begin{array}{l}\text { Mencari } \\
\text { Informasi }\end{array}$ & 35 & 100 \\
Tidak \\
$\begin{array}{l}\text { Mencari } \\
\text { Informasi }\end{array}$ & 0 & 0 \\
\hline \multicolumn{1}{c}{ Total } & 35 & 100 \\
\hline
\end{tabular}

Sumber: Data Primer, Tahun 2016 
Dari Tabel 10 dapat dilihat bahwa seluruh anggota kelompok tani Sarongsong youth menerima informasi yang disampaikan oleh penyuluh, pimpinan, atau anggota kelompok yang ditugaskan mengikuti pelatihan serta kordinator dalam tugas tertentu.

Tabel 11. Persentase Responden Yang Menerima Penjelasan

\begin{tabular}{lcc}
\hline Penjelasan & $\begin{array}{c}\text { Responde } \\
\mathrm{n} \\
\text { (Anggota) }\end{array}$ & $\begin{array}{c}\text { Presentase } \\
(\%)\end{array}$ \\
\hline Menerima & 35 & 100 \\
$\begin{array}{l}\text { Tidak } \\
\text { Menerima }\end{array}$ & 0 & 0 \\
\hline \multicolumn{1}{c}{ Total } & 35 & 100 \\
\hline
\end{tabular}

Sumber: Data Primer, Tahun 2016

Berdasarkan Tabel 11 dapat dilihat bahwa semua anggota menerima penjelasanpenjelasan mengenai informasi yang diterima berdasarkan fungsi memberikan informasi dalam kelompok. Penjelasan ini diberikan saat dilakukan pertemuan kelompok ataupun langsung di lokasi pertanian maupun di lokasi peternakan ayam.

Selain fungsi tugas kelompok dalam memberikan informasi dan menjelaskan, maka fungsi memuaskan setiap anggota kelompok merupakan tolak ukur diterimanya informasi dan penjelasan dalam kelompok, hal ini juga disertai dengan fasilitas yang diterima oleh anggota kelompok tani.

\begin{tabular}{|c|c|c|}
\hline \multicolumn{3}{|c|}{$\begin{array}{c}\text { Tabel 12. Persentase Petani Yang } \\
\text { Merasa Puas akan Informasi, Penjelasan } \\
\text { dan Fasilitas }\end{array}$} \\
\hline $\begin{array}{l}\text { Informasi dan } \\
\text { Fasilitas }\end{array}$ & $\begin{array}{c}\text { Responden } \\
\text { (Anggota) }\end{array}$ & $\begin{array}{c}\text { Presentase } \\
(\%)\end{array}$ \\
\hline Merasa Puas & 35 & 100 \\
\hline $\begin{array}{l}\text { Tidak Merasa } \\
\text { Puas }\end{array}$ & 0 & 0 \\
\hline Total & 35 & 100 \\
\hline
\end{tabular}

Sumber: Data Primer, Tahun 2016

Berdasrakan Tabel 12 dapat dilihat bahwa semua anggota kelompok tani Sarongsong Youth merasa puas akan informasi yang diterima dan bantuan dari pemerintah berupa bantuan bibit cabai, modal usaha dan bibit ternak ayam dirasakan oleh para anggota sangat membantu kelompok tani tersebut.

d. Pembinaan Kelompok. Pembinaan kelompok merupakan usaha-usaha yang bertujuan untuk memelihara dan mengembangkan kelompok. Pembinaan kelompok dalam hal ini merupakan salah satu unsur yang terdiri dari pertemuan kelompok, kegiatan kelompok dan pengawasan kelompok.

Pertemuan kelompok ini masih berkaitan mengenai informasi dan hal-hal yang memiliki hubungan dengan kelompok, pertemuan ini dimaksudkan agar setiap anggota kelompok dapat lebih efisien. Pertemuan kelompok ini ada yang rutin dan ada yang tidak rutin.

Tabel 13. Persentase Responden yang Aktif Mengikuti Pertemuan Kelompok

\begin{tabular}{lcc}
\hline Pertemuan & $\begin{array}{c}\text { Responden } \\
\text { (Anggota) }\end{array}$ & $\begin{array}{c}\text { Presentase } \\
(\%)\end{array}$ \\
\hline Aktif & 35 & 100 \\
Tidak & 0 & 0 \\
Aktif & 35 & 100 \\
\hline \multicolumn{1}{c}{ Total } &
\end{tabular}

Sumber: Data Primer, Tahun 2016 


\section{KESIMPULAN DAN SARAN}

\section{Kesimpulan}

Dinamika kelompok tani Sarongsong Youth di Kelurahan Tumatangtang Satu Kecamatan Tomohon Selatan berada pada kategori yang baik. Hal ini terutama ditunjukan oleh faktor-faktor dinamika kelompok tani selain tekanan pada kelompok, yang disebabkan lebih kepada sub faktor penghargaan yang masih kurang baik.

\section{Saran}

Dinamika kelompok tani Sarongsong Youth perlu ditingkatkan lagi, apalagi dalam faktor tekanan pada kelompok. Sebaiknya diberikan penghargaan tersendiri bagi anggota kelompok yang lainnya agar dapat memberikan motivasi yang lebih lagi bagi mereka yang pantas, terutama ketika ada yang memberikan kontribusi lebih pada kelompok.

\section{DAFTAR PUSTAKA}

Diniyati, 2001. Dinamika Kelompok Tani Hutan Rakyat: Studi Kasus di Desa Kertayasa, Boja dan Sukorejo.Jurnal Kehutanan2.4 .

Gibson dan Donnelly, 2006. Organisasi dan Manajemen : Perilaku, Struktur dan Proses. Erlangga : Jakara.

Hutauruk, Erwin Hasudungan 2009. Pengaruh Pendidikan Dan Pengalaman Petani Terhadap Tingkat Produktivitas Tanaman Kopi Dan Kontribusinya Terhadap Pengembangan Wilayah Di Kabupaten Tapanuli Utara. Skripsi.
Mardikanto, L. 2009. Sistem Penyuluhan Pertanian. Sebelas Maret University Press: Surakarta.

Mayasari, dan Nangameka 2015. Pengaruh Keberadaan Kelompok Tani Terhadap Pendapatan Usaha Tani Tembakau (Studi Kasus di Desa Tlogosari Kecamatan Sumbermalang).

Nuryanti, Sri, dan Swastika. Peran Kelompok Tani dalam Penerapan Teknologi Pertanian.Forum Penelitian Agro Ekonomi.Vol. 29.No. 2. 2011.

Santoso, S. 2004. Dinamika Kelompok (revisi). Bumi Askara ISBN: 979526964x

Setiadi, H. 2005. Faktor-faktor yang Mempengaruhi Anggota Kelompoktani dalam Berusahatani (Kasus Usahatani Ikan Tawar di Desa Purwasari Kabupaten Darmaga Bogor, Jawa Barat).Tesis.Bogor : IPB.

Slamet, M. 2001. Paradigma Penyuluhan Pertanian dalam Era Otonomi Daerah.Makalah Pelatihan Penyuluhan Pertanian di Universitas Andalas.

Soedarsono, T. 2005. Dinamika Kelompok.Universitas Terbuka: Jakarta

Soekanto, S. 2006. Sosiologi Suatu Pengantar. PT. Raja Grafindo Persada cetakan ke-30: Jakarta. 
2002. Kumpulan Bahan Kuliah : Kelompok, Organisasi dan Kepemimpinan.IPB: Bogor

Suhardiyono . 1992. Penyuluhan : Petunjuk bagi Penyuluh Pertanian. Erlangga: Jakarta
Tampubolon, Joyakin, et al 2016. "Pemberdayaan Masyarakat Melalui Pendekatan Kelompok (Kasus Pemberdayaan Masyarakat Miskin melalui Pendekatan Kelompok Usaha Bersama (KUBE))." Jurnal Penyuluhan 2.2. 